\title{
Estudo bibliométrico e sistêmico da literatura sobre a integração de métodos quantitativos e qualitativos na previsão de demanda com ajuste de especialistas
}

\author{
Bibliometric and systemic study of the literature on the \\ integration of quantitative and qualitative methods in \\ the forecast for demand with adjustment of specialists
}

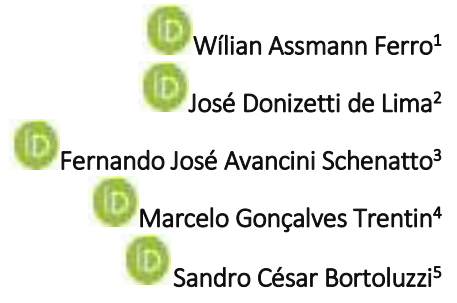

${ }^{1}$ Mestre em Engenharia de Produção e Sistemas (UTFPR). Bolsista do Programa de Pós-graduação em Engenharia de Produção e Sistemas - PPGEPS. Universidade Tecnológica Federal do Paraná (UTFPR). Pato Branco - Paraná - Brasil. engqmc_wilian@hotmail.com

${ }^{2}$ Doutor em Engenharia de Produção (UFRGS). Professor do Departamento de Matemática e vice-coordenador do PPGEPS. Universidade Tecnológica Federal do Paraná (UTFPR). Pato Branco

Paraná - Brasil

donizetti@utfpr.edu.br

${ }^{3}$ Doutor em Engenharia de Produção (UFSC). Professor titular do Departamento Acadêmico de Elétrica - DAELE; e Coordenador do Programa de Pós-graduação em Engenharia de Produção e Sistemas - PPGEPS. Universidade Tecnológica Federal do Paraná (UTFPR). Pato Branco - Paraná - Brasil. schenatto@utfpr.edu.br

${ }^{4}$ Doutor em Engenharia de Produção (UFRGS). Professor do Programa de Pós-Graduação Em Engenharia de Produção - PPGEPS Universidade Tecnológica Federal do Paraná (UTFPR). Pato Branco -

Paraná - Brasil

marcelo@utfpr.edu.br

${ }^{5}$ Doutor em Engenharia de Produção (UFSC). Diretor de Pesquisa e Pós-graduação (UTFPR) - Câmpus Pato Branco. Universidade Tecnológica Federal do Paraná (UTFPR). Pato Branco-Paraná-Brasil. sandro@utfpr.edu.br

\begin{abstract}
Resumo
O presente artigo visa encontrar uma possível lacuna de pesquisa dentro da temática "integração de métodos de previsão de demanda quantitativos e qualitativos com ajuste de especialistas". Para isso, utilizou-se da análise bibliométrica e de conteúdo que foi elaborada, por meio da aplicação da metodologia Proknow-C (Knowledge Development Process - Constructivist) e análise categorial. Os principais resultados encontrados sobre a temática foram: (i) selecionou-se um portfólio bibliográfico contendo 21 artigos; (ii) o International Journal of Forecasting foi identificado como o principal periódico; (iii) os autores destaque são Armstrong Scott J.; Goodwin, Paul e Lawrence, Michael. O emprego da metodologia Proknow-C permitiu contribuir cientificamente com um processo estruturado sobre o tema integração de métodos de previsão de demanda. Já a análise de conteúdo, permitiu encontrar como oportunidade de pesquisa: a integração de métodos quantitativos e qualitativos para previsão de demanda com ajuste de especialistas via método multicritério de apoio a tomada de decisão.
\end{abstract}

Palavras-chave: Proknow-C. Previsão de demanda. Métodos quantitativos. Métodos qualitativos. Integração de previsão.

\begin{abstract}
The present article aims to find a possible research gap within the theme "integration of quantitative and qualitative demand forecasting methods with expert adjustment". For this, we used bibliometric analysis and content that was elaborated through the application of Proknow-C (Knowledge Development Process - Constructivist) methodology and categorical analysis. The main results found on the subject were: (i) a bibliographic portfolio was selected containing 21 articles; (ii) the International Journal of Forecasting was identified as the main journal; (iii) the prominent authors are Armstrong Scott $J$; Goodwin, Paul and Lawrence, Michael. The use of the Proknow-C methodology made it possible to contribute scientifically to a structured process on the topic integration of demand forecasting methods. On the other hand, the content analysis allowed us to find as a research opportunity: the integration of quantitative and qualitative methods for forecasting demand with expert adjustment through a multicriteria method to support decision making
\end{abstract}

Keywords: Proknow-C. Forecast of demand. Quantitative methods. Qualitative methods. Forecast integration. 
1 Introdução

A habilidade para antever eventos futuros constitui umas das mais antigas virtudes gerenciais. Diante das constantes evoluções que o mundo vem sofrendo, é necessário que a tomada de decisão seja planejada (Werner, 2004). Para isso, é importante entender a dinâmica da previsão de demanda que, em um primeiro momento pode ser entendida como a quantidade que é vendida de um determinado produto ou serviço. Contudo, esse conceito é mais amplo e engloba questões econômicas, sociais e legais. Assim, para prever a demanda, é necessária uma análise completa dos atores e variáveis envolvidas no negócio (Green \& Armstrong, 2011).

Diante disso e considerando o ambiente de negócios atual, que é caracterizado por incerteza e tempos de resposta curtos, a capacidade de prever as futuras demandas, tornou-se uma tarefa crítica dentro das organizações (Sanders \& Ritzman, 2004). Nesse contexto, a falta da previsão de demanda provoca impactos negativos na compra de matérias-primas, na definição da mão de obra e perdas financeiras e de produtividade afetando assim o planejamento e tomada de decisão das empresas.

Para assegurar a qualidade e a produtividade e fazer disto uma vantagem competitiva, a previsão de demanda torna-se indispensável nas organizações, pois todas as áreas das empresas fazem, direta ou indiretamente uso dela para dimensionar o volume de produção, formalizar estratégias de marketing ou planejar o fluxo financeiro (Makridakis et al., 1998; Pellegrini \& Fogliatto, 2001; Werner \& Ribeiro, 2006). Logo, torna-se necessário utilizar estratégias, que viabilizem determinar com precisão a demanda.

Assim, uma alternativa que se apresenta dentre várias existentes é a previsão de demanda integrada por métodos estatísticos, juntamente com o julgamento de especialistas. Essa integração proporciona melhorias na precisão das previsões, pois incorpora os benefícios das duas metodologias (Webby \& O'connor, 1996; Goodwin, 2002). Dentro deste contexto Lawrence et al. (2006), destacam que, para implementar um efetivo sistema de previsão de demanda envolvendo julgamentos, os mesmos devem ser gerenciados.

Portanto, o interesse no tema da pesquisa, integração de métodos quantitativos e qualitativos na previsão de demanda com ajuste de especialistas justifica-se, pois, apesar do tema ser largamente estudado (Webby \& O'connor, 1996; Lawrence et al., 2006; Gooijer \& Hyndman, 2006; Wallis, 2011; Mancuso \& Werner, 2013; Santos et al., 2015), ainda necessita de aprofundamentos no tocante a acuracidade das previsões a fim de esclarecer possíveis lacunas científicas.

Dentro deste contexto, surge o questionamento da pesquisa: como identificar lacunas científicas dentro da temática integração de métodos quantitativos e qualitativos para previsão de demanda com ajuste de especialistas?

Para encontrar a resposta do questionamento, tem-se como objetivo: selecionar, por meio de um processo estruturado, um portfólio de artigos, alinhados com a temática: integração de métodos quantitativos e qualitativos para previsão de demanda com ajuste de especialistas. Já os objetivos específicos são: (i) analisar esse portfólio por meio da análise bibliométrica, com a finalidade de evidenciar os principais artigos, autores e periódicos sobre o tema; (ii) realizar uma análise de conteúdo que permita encontrar a lacuna científica para o desenvolvimento de novas pesquisas.

Diante do exposto, para construir o portfólio bibliográfico e a partir deste encontrar a lacuna científica sobre o tema mencionado, será utilizando: i) uma abordagem quantitativa baseada na metodologia Proknow-C, Knowledge Development Process-Constructivist (Ensslin et al., 2010); ii) uma abordagem qualitativa adotando a análise de conteúdo baseada na técnica de análise categorial (Bardin, 2011). Como delimitação da pesquisa, a 
busca pelos artigos ocorre na base de dados da Coordenação de Aperfeiçoamento de Pessoal de Nível Superior (CAPES) e nas bases de dados: Web of Science, Wiley Online Library e Scopus.

\section{Referencial teórico}

\subsection{Proknow-C (Knowledge Development Process-Constructivist)}

O Proknow-C é uma metodologia utilizada para formação e análise de um portfólio bibliográfico que foi originado e desenvolvido, nos anos de 2005 e 2006, no Laboratório de Metodologias Multicritério em Apoio à Decisão (LabMCDA) pertencente ao Departamento de Engenharia de Produção e Sistemas da Universidade Federal de Santa Catarina (UFSC) (Ensslin, et al., 2010; Bortoluzzi et al., 2011). A estrutura base da metodologia Proknow-C pode ser visualizada na Figura 1.

Figura 1 - Macro fases da metodologia Proknow-C

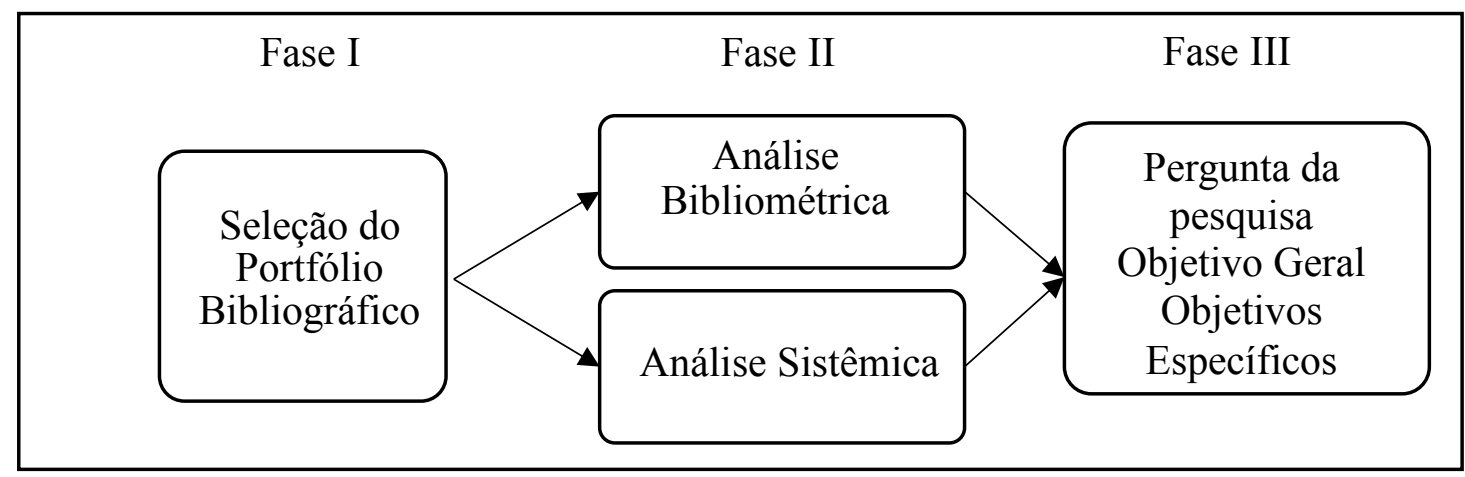

Fonte: Adaptado de Ensslin et al. (2010).

Com relação ao detalhamento das fases da metodologia Proknow-C, da Figura 1, a Fase I - Seleção do Portfólio Bibliográfico é desdobrada nos seguintes passos: (i) definição dos eixos de pesquisa; (ii) definição das palavras-chave; (iii) Seleções da base de dados; (iv) formação do banco de dados de artigos brutos; e (v) análise dos artigos do banco de artigos brutos. Já a Fase II - Análise Bibliométrica é desdobrada nos seguintes passos: (i) relevância dos periódicos dentro do portfólio bibliográfico; (ii) reconhecimento científico dos artigos no portfólio bibliográfico; (iii) relevância dos autores do portfólio bibliográfico; e (iv) análise cruzada dos periódicos e artigos destaque.

Nesse contexto, cabe ressaltar que o Proknow-C é amplamente utilizado no meio acadêmico, com destaque para as publicações de (Ensslin, et al., 2010; Tasca et al., 2010; Bortoluzzi et al., 2011; Vilela, 2011; Ensslin, et al., 2013; Lizot et al., 2015; Gularte, et al., 2018). Por fim, a Fase II - Análise sistêmica e a Fase III Obtenção da lacuna científica não utilizam o Proknow-C. Para mais detalhes sobre a utilização do Proknow-C consultar (Ensslin et al., 2010). 
De acordo com Carlomagno \& Rocha (2016), a análise de conteúdo se destina a classificar e categorizar qualquer tipo de conteúdo, reduzindo suas características a elementos-chave, de modo que sejam comparáveis a uma série de outros elementos. Para Bardin (1977) a análise de conteúdo é composta por um conjunto de técnicas de análise das comunicações que, por meio de procedimentos sistemáticos, visa obter a descrição do conteúdo e posteriormente, indicadores que permitam fazer inferências sobre determinada mensagem.

Além disso, Bardin (1977), salienta que para realizar a análise de conteúdo deve-se: (i) descrever as categorias; (ii) realizar as inferências; e (iii) interpretar. Diante disso, Bardin (2011), no Quadro 1, apresenta os critérios de escolha das categorias (classificação e agregação) em que as mesmas são vistas como rubricas ou classes que agrupam determinados elementos reunindo características comuns.

Quadro 1 - Critérios de qualidade de escolha das categorias

\begin{tabular}{|l|l|}
\hline \multicolumn{1}{|c|}{ Critérios de qualidade } & \multicolumn{1}{c|}{ Descrição } \\
\hline A exclusão mútua & $\begin{array}{l}\text { Ser classificada em apenas uma categoria. Não existir } \\
\text { ambiguidades. }\end{array}$ \\
\hline A pertinência & $\begin{array}{l}\text { A categoria é pertinente ao material escolhido, e quando } \\
\text { pertence ao quadro teórico definido. }\end{array}$ \\
\hline A objetividade e a fidelidade & $\begin{array}{l}\text { O pesquisador deve definir claramente as variáveis que } \\
\text { trata, assim como deve precisar os índices que determinam } \\
\text { a entrada de um elemento numa categoria. }\end{array}$ \\
\hline A produtividade & $\begin{array}{l}\text { Um conjunto de categorias é produtivo se fornece: índices } \\
\text { de inferências, hipotéses novas ou dados exatos. }\end{array}$ \\
\hline
\end{tabular}

Fonte: Adaptado de Bardin, (2011).

Após a definição das categorias, é necessário que as mesmas permitam gerar inferências sobre o conteúdo categorizado. Bardin (2011), apresenta duas formas de inferências: (i) específica: que é exemplificada por meio de uma pergunta focada em um propósito; (ii) geral: quando se pretende identificar se existe uma correlação entre as categorias. Dessa forma, aplicando a análise de conteúdo, com base nas categorias e posteriormente fazendo as inferências do conteúdo, existe a possibilidade de encontrar uma lacuna científica sobre uma determinada temática.

Nesse contexto, é importante destacar que a análise de conteúdo é amplamente utilizada no meio acadêmico. Meireles \& Cendón, (2010) aplicaram a análise de conteúdo em artigos relacionados às redes neurais artificiais e as categorias utilizadas foram: "característica funcional da RNA", "arquitetura da RNA" e "algoritmo de aprendizado".

Já Urquiza \& Marques (2016), aplicaram a análise de conteúdo na comunicação corporativa. As categorias definidas foram as seguintes: (i) zelo profissional; (ii) a ideologia do resultado sustentável; (iii) o imaginário do gestor qualificado; (iv) projeção da imagem institucional desejada sobre os funcionários; e (v) concordância cultural. Para mais detalhes sobre a utilização da Análise de Conteúdo, consultar (Bardin, 2011). 


\section{Procedimentos metodológicos}

O primeiro objetivo desse estudo é formar um portfólio bibliográfico voltado ao tema: integração de métodos de previsão de demanda quantitativos e qualitativos com ajuste de especialistas. Para isso, optou-se pela utilização da metodologia Proknow-C, pois essa abordagem construtivista possibilita melhorar a compreensão e a elaboração do conhecimento sobre o tema (Marafon et al., 2012; Lizot et al., 2015).

Nesse trabalho será utilizado, conforme destaca a Figura 1, a Fase I - Seleção do Portfólio e a análise bibliométrica da Fase II. A análise sistêmica das Fases II e III, não seguiram a abordagem Proknow-C. Isso ocorreu em virtude de que as lentes utilizadas na análise de conteúdo não permitem realizar a categorização satisfatória dos artigos do portfólio bibliográfico. Com isso cria empecilhos para encontrar a lacuna científica do trabalho. Portanto, a análise de conteúdo é baseada na técnica: análise categorial, que de acordo com Bardin (2011), tem por base o desmembramento do texto em categorias.

\subsection{Procedimentos para seleção do portfólio bibliométrico - FASE I}

\subsubsection{Definição dos eixos de pesquisa}

O ponto inicial da pesquisa consiste em definir os eixos. Como o tema proposto é a integração de métodos quantitativos e qualitativos para previsão da demanda com ajuste de especialista, os e, as palavras que compõem os eixos foram traduzidas para língua inglesa e são as seguintes:

i. $\quad$ Combinação de previsões - Combining Forecast;

ii. Integração de previsões - Integrate Forescast;

iii. Previsão de demanda - Demand Forescast.

\subsubsection{Definições das palavras-chave}

Para definir as palavras-chave utilizou-se o mesmo critério de escolha dos eixos da pesquisa. Por meio das palavras-chave, expostas na Figura 2, realizou-se a pesquisa nas bases de dados mencionadas no item 2.3.

Figura 2 - Eixos e palavras-chave da pesquisa

\begin{tabular}{ccc}
\hline $1^{\circ}$ Eixo & $2^{\circ}$ Eixo & $3^{\circ}$ Eixo \\
\hline Integrate & Combining forecasting & Demand forecasting \\
Integrate forecasting & Combining or Combine or Combination & Forecasting or Forecast \\
Qualitative methods & Quantitative methods & Time series \\
Judgment or Judmental & & \\
\hline
\end{tabular}

Fonte: Dados da pesquisa.

\subsubsection{Seleções da base de dados}

Para a realização desta pesquisa optou-se pelas seguintes bases de dados: Web of Science, Wiley Online Library e Scopus, pois as mesmas estão alinhadas com o tema da pesquisa, disponíveis no portal periódicos da 
CAPES e são as mais relevantes no contexto internacional.

\subsubsection{Formação do banco de dados de artigos brutos}

Para formar a base de artigos brutos realizou-se a pesquisa durante o mês de junho de 2016. Por meio das palavras-chave e eixos da pesquisa, obteve-se 36 combinações. Não se aplicou nenhum filtro para as palavraschave do primeiro eixo, porém às palavras-chave do segundo eixo foi aplicado o filtro "título", considerando somente as palavras presentes nos títulos dos artigos.

Com relação às palavras-chave do terceiro eixo aplicou-se o filtro "título, resumo e palavras-chave" para a base Scopus; já para a base Wiley Online Library, aplicou-se o filtro "resumo"; e para base Web of Science aplicouse o filtro "título". Para todas as combinações entre os eixos, foi aplicado o operador booleano "and" e entre as palavras-chave o operador booleano "or". Por meio da Figura 3, é exemplificado o processo de combinação das palavras-chave nas bases de dados.

Com base nos exemplos de combinações realizados na Figura 3, replicou-se para as demais, 36 combinações. A busca pelos resultados considerou somente "articles e reviews". Para "área do conhecimento" não foi aplicado nenhuma restrição, logo a pesquisa abrangeu todas as áreas. Com relação à temporalidade, a pesquisa abrangeu o período compreendido entre 1990 e 2016 totalizando 27 anos, visto que, até o ano de 1989, já existe um amplo trabalho de revisão da literatura, totalizando a análise de 209 artigos, sobre os métodos de combinações de previsão de demanda incluindo também o julgamento de especialistas, realizado por Clemen (1989). Assim, obteve-se um número total de 1.104 artigos.

Figura 3 - Combinação das palavras-chave nas bases de dados

\begin{tabular}{|c|c|c|c|c|c|c|c|c|c|c|}
\hline Filtro & $1^{\circ}$ Eixo & Op. & Filtro & $2^{\circ}$ Eixo & Op. & Filtro & $3^{\circ}$ Eixo & $\begin{array}{l}\text { Wiley Online } \\
\text { Library }\end{array}$ & Scopus & $\begin{array}{l}\text { Web of } \\
\text { Science }\end{array}$ \\
\hline Todos & Integrate & and & Titulo & $\begin{array}{c}\text { Forecasting or } \\
\text { Forecast }\end{array}$ & and & $\begin{array}{l}\text { Titulo, Resumo, } \\
\text { palavras-chave }\end{array}$ & $\begin{array}{l}\text { Combining or } \\
\text { Combine or } \\
\text { Combination }\end{array}$ & 256 & 36 & 67 \\
\hline Todos & Integrate & and & Titulo & "Time Series" & and & $\begin{array}{l}\text { Titulo, Resumo, } \\
\text { palavras-chave }\end{array}$ & $\begin{array}{c}\text { Combining or } \\
\text { Combine or } \\
\text { Combination }\end{array}$ & 85 & 13 & 13 \\
\hline Todos & $\begin{array}{l}\text { Judgment or } \\
\text { Judgmental }\end{array}$ & and & Titulo & $\begin{array}{c}\text { Forecasting or } \\
\text { Forecast }\end{array}$ & and & $\begin{array}{l}\text { Titulo, Resumo, } \\
\text { palavras-chave }\end{array}$ & $\begin{array}{l}\text { Combining or } \\
\text { Combine or } \\
\text { Combination }\end{array}$ & 42 & 193 & 25 \\
\hline
\end{tabular}

Fonte: Elaborado pelo autor.

A fim de confirmar a aderência das palavras-chave com o tema, escolheram-se dois artigos de forma aleatória (Graefe et al., 2014; Saccani, 2011) e verificou-se que as palavras-chave escolhidas estão de acordo e assim não foram adicionadas novas palavras-chave. 


\subsubsection{Análise dos artigos do banco de artigos brutos}

Na primeira análise do banco de artigos brutos realizou-se a verificação dos artigos duplicados. Com auxílio do software de gerenciamento bibliográfico Mendeley", foi possível eliminar 387 artigos duplicados, restando 717 artigos não repetidos. Na sequência, realizou-se a leitura dos 717 títulos dos artigos do banco de dados de artigos brutos, sendo que foram retirados do portfólio 605 artigos, os quais não estão alinhados com o tema da pesquisa, restando assim, 112 artigos.

Posteriormente verificou-se o reconhecimento científico desses 112 artigos. Para isso, efetuou-se uma pesquisa no Google Acadêmico (GOOGLE, 2016), o qual quantifica o número de citações totais das referências pesquisadas. Por meio da análise dos 112 artigos, encontrou-se um total de 4.764 citações. Conforme ilustra a Figura 4, determinou-se que os artigos com menos de 5 citações fossem eliminados. Isso ocorreu em 41 artigos, 1,54\% do total das citações. Por outro lado, 71 artigos apresentavam título e reconhecimento científico que estão alinhados com o tema da pesquisa, isso representa um total de 98,46\% das citações. De acordo com Lacerda et al., (2012) "se a pesquisa selecionar a minoria dos artigos mais citados, esses representam a maioria do reconhecimento científico presente no conjunto atual de artigos".

Figura 4 - Reconhecimento científico dos artigos

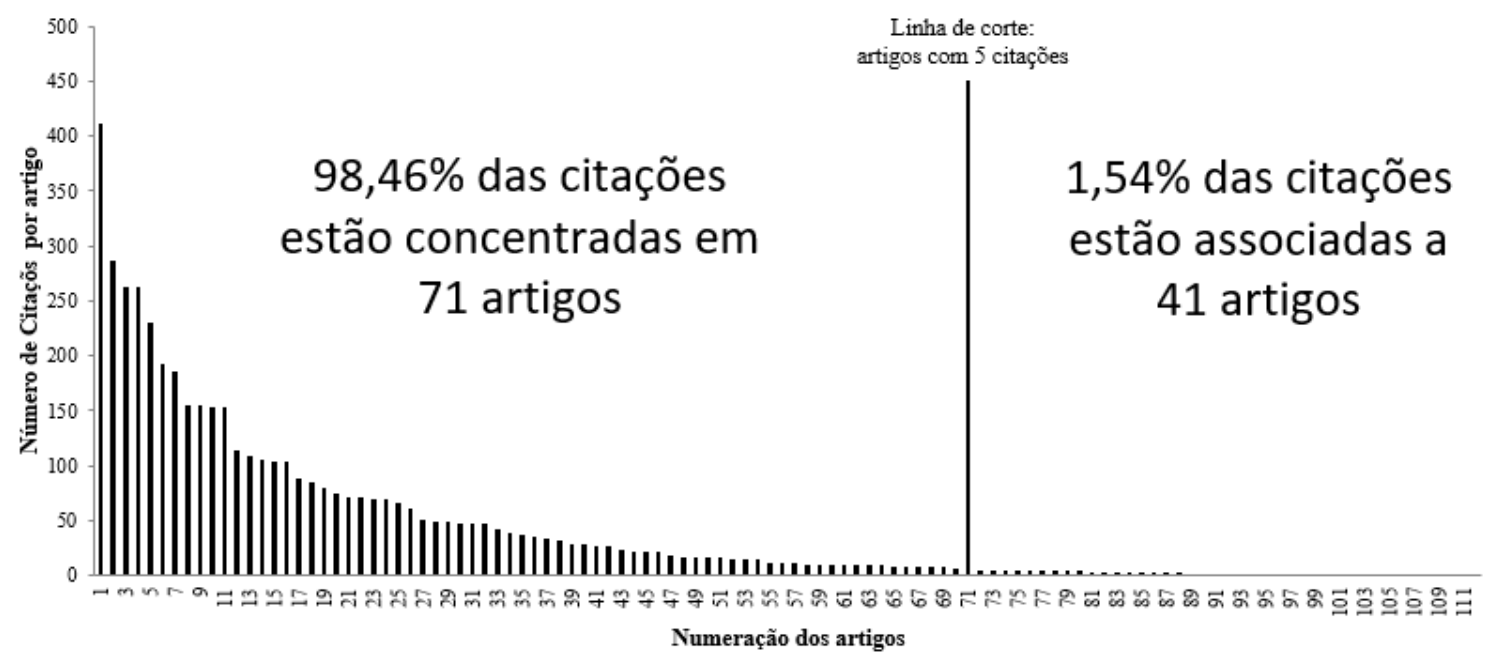

Fonte: Elaborado pelo autor.

Após o reconhecimento científico de 71 artigos, iniciou-se a leitura dos resumos. Esse procedimento resultou na remoção de 46 artigos do portfólio. Assim, para formar o banco de dados de artigos brutos com título, reconhecimento científico e resumos alinhados com o tema da pesquisa manteve-se um total de 25 artigos.

Por meio desses 25 artigos elaborou-se a lista de autores, totalizando 39 autores. Na sequência, com o intuito de verificar, se nos 41 artigos sem reconhecimento científico, existe algum alinhado com o tema da pesquisa, foram efetuados dois procedimentos: 
a) Separação dos artigos com menos de dois anos da publicação. Neste caso, obteve-se 19 artigos que, após a leitura dos resumos, não se identificou nenhum alinhado com o tema da pesquisa;

b) Verificou-se a presença dos 39 autores nos artigos sem reconhecimento científico. Após confrontar os nomes não se encontrou nenhum artigo que contivesse os autores supracitados. Logo, não foi adicionado nenhum artigo à base de dados de artigos brutos.

Dessa forma, não se incluiu nenhum artigo ao portfólio bibliográfico. Na próxima etapa, efetuou-se a leitura completa desses 25 artigos, sendo que por meio deste procedimento foram eliminados 4 artigos que não estão alinhados com o tema da pesquisa. Para compor o portfólio bibliográfico, após todas as etapas, obteve-se um total de 21 artigos, conforme destaca o Quadro 2. 
Quadro 2 - Portfólio bibliométrico do tema: integração de métodos quantitativos e qualitativos para previsão de demanda com ajustes de especialistas

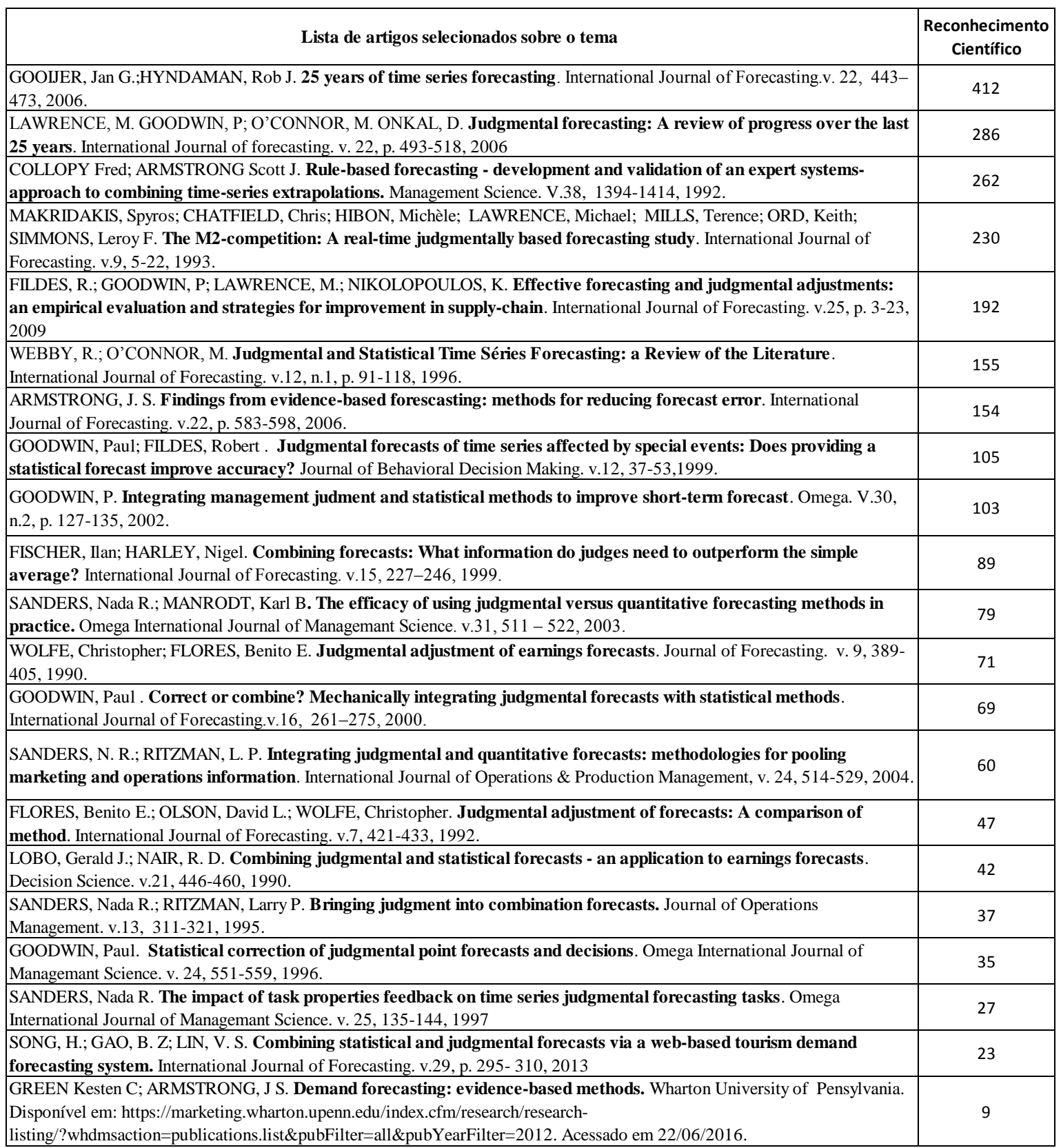

Fonte: Elaborado pelo autor.

\subsection{Procedimentos para análise bibliométrica e de conteúdo (sistêmica) - FASE II}

Na Fase II, da Figura 1, a análise bibliométrica segue a abordagem Proknow-C. De acordo com Ensslin, Ensslin, Lacerda \& Tasca (2010), a Análise Bibliométrica busca desenvolver um maior entendimento a respeito de um portfólio de artigos, em que dados estatísticos são estratificados, tendo como base: (i) Relevância dos periódicos; (ii) Reconhecimento científico dos artigos; (iii) Relevância dos autores; e (iv) Análise cruzada dos periódicos e artigos destaque.

Por outro lado, com relação à análise sistêmica presente na Figura 1, Fase II, não segue a abordagem Proknow-C. Isso ocorreu em virtude de que as lentes utilizadas na análise de conteúdo não permitem realizar a categorização satisfatória dos artigos do portfólio bibliográfico. Com isso cria empecilhos para encontrar a lacuna 
científica do trabalho. Portanto, a análise de conteúdo é baseada na técnica: análise categorial, que de acordo com Bardin (2011), tem por base o desmembramento do texto em categorias que no presente trabalho foram as seguintes: (i) revisões, resumos ou análise teórica; (ii) abordagem qualitativa ou quantitativa; (iii) método de integração; (iv) estrutura dos julgamentos; e (v) melhorias nas previsões.

\section{Resultados e discussões \\ 4.1 Análise bibliométrica}

De posse dos 21 artigos do portfólio bibliográfico, iniciou-se a análise bibliométrica. Esse procedimento possibilita a ampliação do conhecimento sobre o tema e também obter informações sobre artigos, periódicos e autores mais relevantes para a pesquisa (Ensslin, 2010). Para sistematizar, a aplicação da metodologia ProknowC, realizar-se-á as seguintes fases:

a) Relevância dos periódicos dentro do portfólio bibliográfico;

b) Reconhecimento científico dos artigos no portfólio bibliográfico;

c) Relevância dos autores do portfólio bibliográfico; e

d) Análise cruzada dos periódicos e artigos destaque.

\subsubsection{Relevância dos periódicos dentro do portfólio bibliográfico}

Nesta fase, busca-se identificar qual periódico tem mais importância dentro do portfólio bibliográfico. De acordo com a Figura 5, pode-se evidenciar que o periódico "International Journal of Forecasting" apresenta maior relevância, pois detêm 47,61\% dos artigos, perfazendo um total de 10 artigos. Esse periódico é o principal Journal da área de métodos de previsão. Outro periódico de destaque é o "Omega International Journal of Management Science" com uma representatividade de 19,04\%, isto é, 4 artigos dentro do portfólio bibliográfico. 
Figura 5- Quantidade de artigos por periódico dentro do portfólio bibliográfico

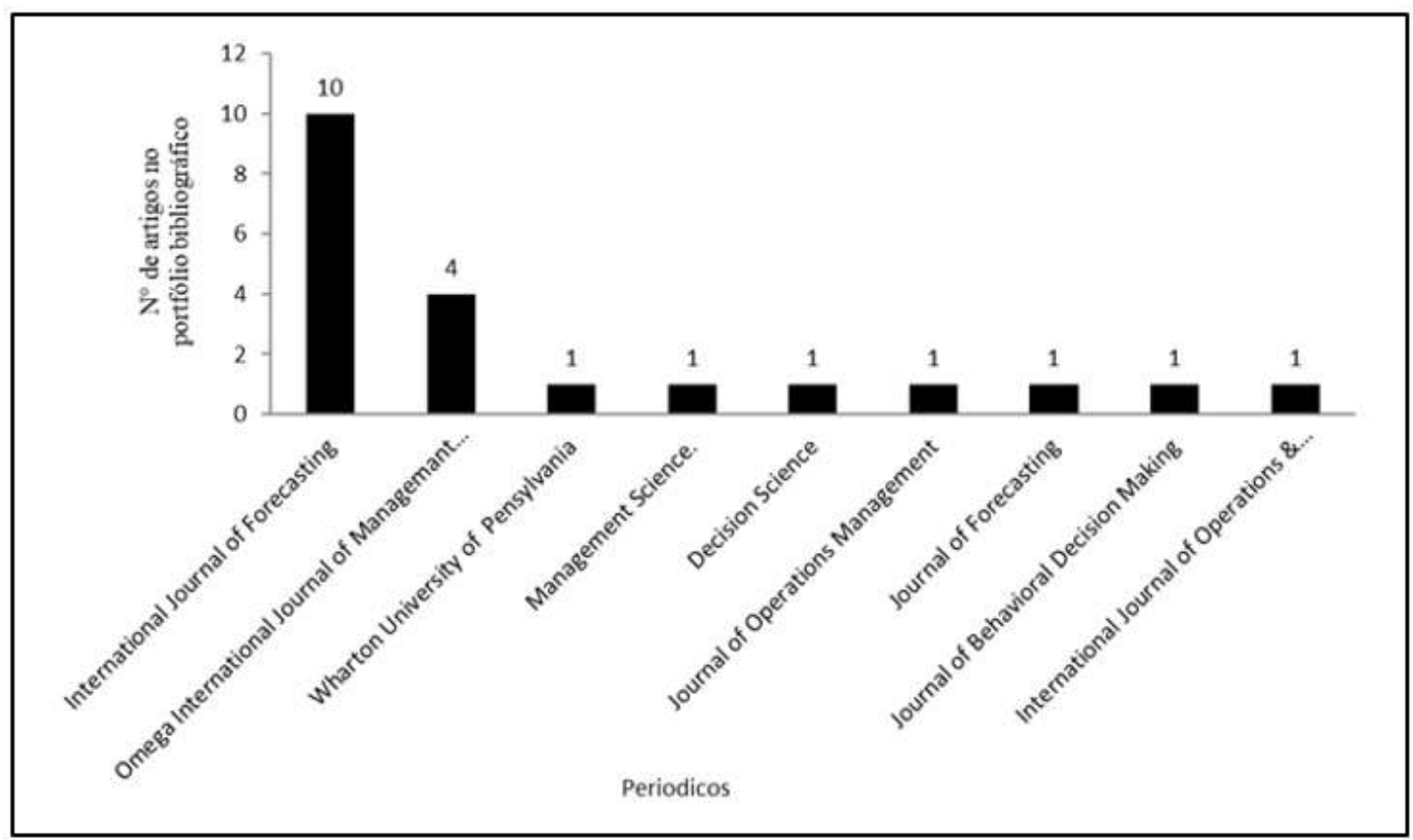

Fonte - Elaborado pelo autor.

\subsubsection{Reconhecimento científico dos artigos no portfólio bibliográfico}

Nesta etapa, buscou-se identificar o reconhecimento científico dos artigos do portfólio bibliográfico. Conforme exposto na Figura 6, pode-se visualizar que o artigo "25 years of time series forecasting" de 2006 dos autores (Gooijer, J. G. \& Hyndman, R. J.) publicado no periódico "International Journal of Forecasting" apresenta o maior número de citações: 412. A força desse artigo ocorre devido à extensa revisão da literatura feita sobre o tema desde 1981 até 2006, aliado ao fato de já estar publicado há mais de 10 anos. 


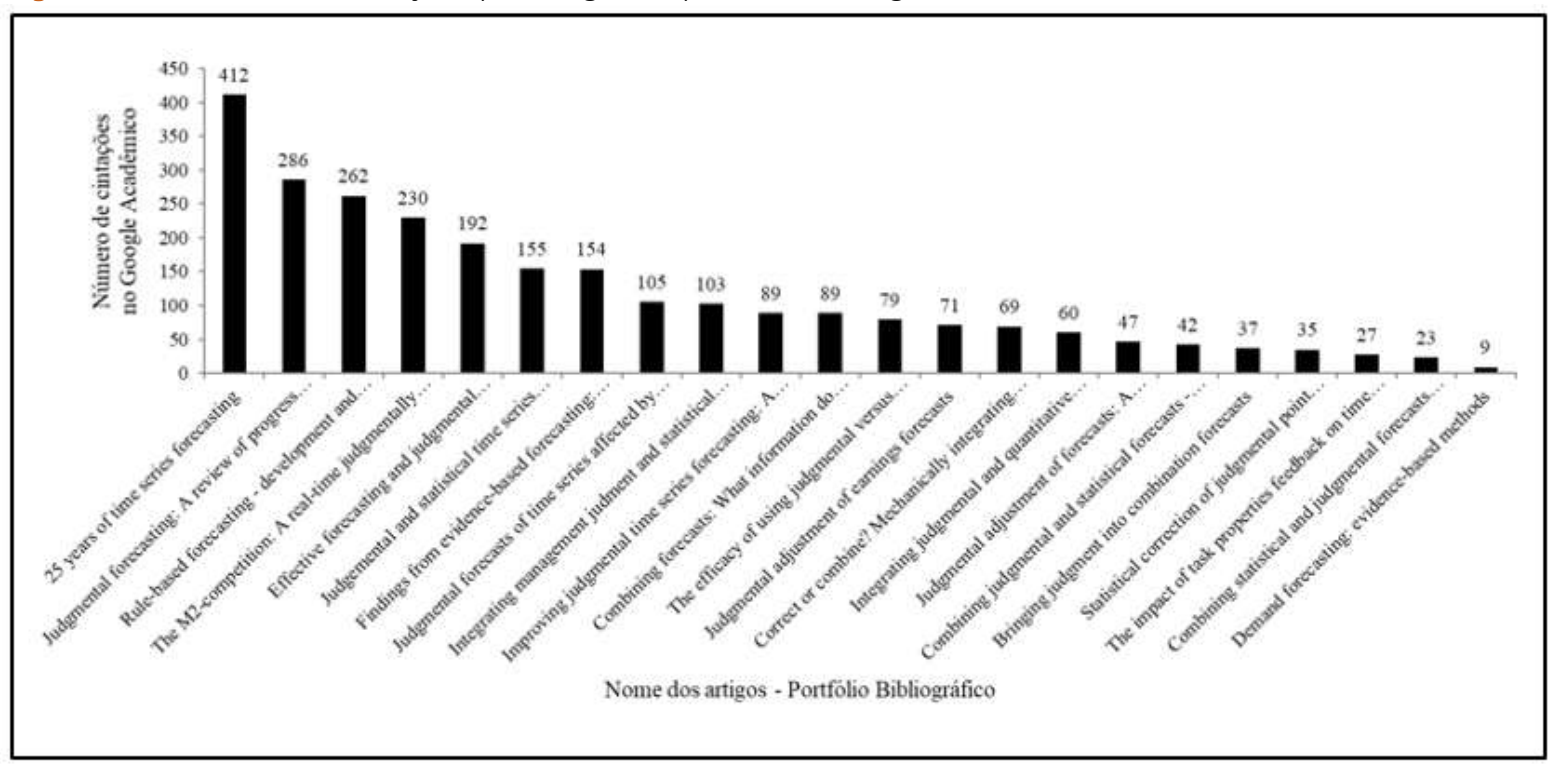

Fonte - Elaborado pelo autor.

Além disso, a Figura 6 mostra que o artigo "Demand forecasting: evidence-based methods" de 2011 dos autores (Green, K. C. \& Armstrong, S. J.) publicado por intermédio da "Wharton University of Pensy/vania" apresentou o menor número de citações. Isto é explicado devido ao fato do artigo conter como autor principal (Green, K. C.) e estar disponível no site da universidade "Wharton University of Pensy/vania". Este mesmo artigo no Google acadêmico apresenta 53 citações, considerando como autor principal (Armstrong, S. J.), porém não foi possível obter o artigo completo de uma fonte confiável, assim considerou-se a primeira opção. Os demais artigos apresentam número relevante de citações.

\subsubsection{Autores referência dentro do portfólio bibliográfico}

A fim de evidenciar e direcionar o conhecimento referente aos principais autores do tema da pesquisa realizou-se o cruzamento dos autores presentes no portfólio bibliográfico com o número de publicações desses autores nas referências dos artigos do portfólio bibliográfico. De acordo com a Figura 7, é possível evidenciar que os autores de destaque, dentro do portfólio bibliográfico e nas referências, são Armstrong S. J.; Goodwin, P. e Lawrence, M., sendo que o número de artigos no portfólio bibliográfico e referências do portfólio são respectivamente (3 e 79; 6 e 58; 3 e 60).

Além do mais, os autores, O'connor, M e Fildes, R. são destaques nas referências do portfólio bibliográfico, sendo que o primeiro possui 51 e o segundo 50 artigos. Por fim, a Figura 7 permite identificar os autores relevantes para o tema da pesquisa que são respectivamente, Flores, B. E.; Ritzman, L.P. e Collopy, F. Além disso, Sanders, N. R é destaque no portfólio bibliográfico. 
Figura 7 - Autores de destaque do portfólio bibliográfico e suas referências

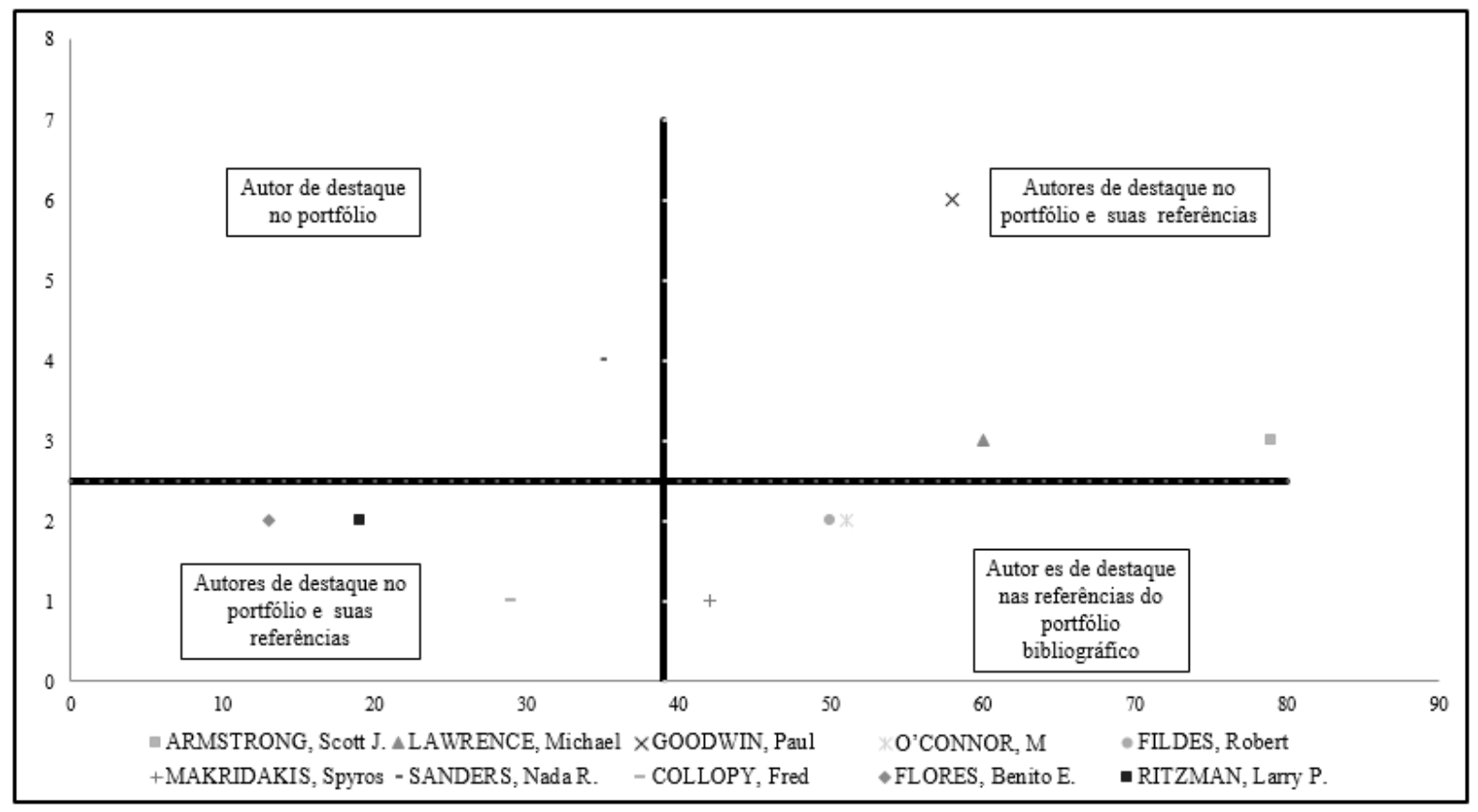

Fonte: Elaborado pelo autor.

\subsubsection{Periódicos e artigos em destaque nas referências no portfólio}

Com o intuito de identificar quais são os periódicos relevantes dentro do tema da pesquisa, integração de métodos quantitativos e qualitativos para previsão de demanda com ajuste de especialistas e para direcionar o envio de artigos para publicação, efetuou-se os cruzamentos dos periódicos presentes no portfólio bibliográfico, com os periódicos presentes nas referências do portfólio bibliográfico.

Por meio da análise da Figura 8, constata-se que o periódico de destaque no portfólio bibliográfico e nas referências é o International Journal of Forecasting, com 10 e 500 citações, respectivamente no portfólio bibliográfico e nas referências. Além disso, o periódico destaque nas referências é o Journal of Forecasting com 1 citação no portfólio e 164 citações nas referências. Por outro lado, o periódico de destaque no portfólio bibliográfico é Omega International Journal of Management Science, com 4 citações no portfólio e 22 nas referências. 
Figura 8 - Grau de relevância dos periódicos presentes nos artigos e referências do portfólio bibliográfico

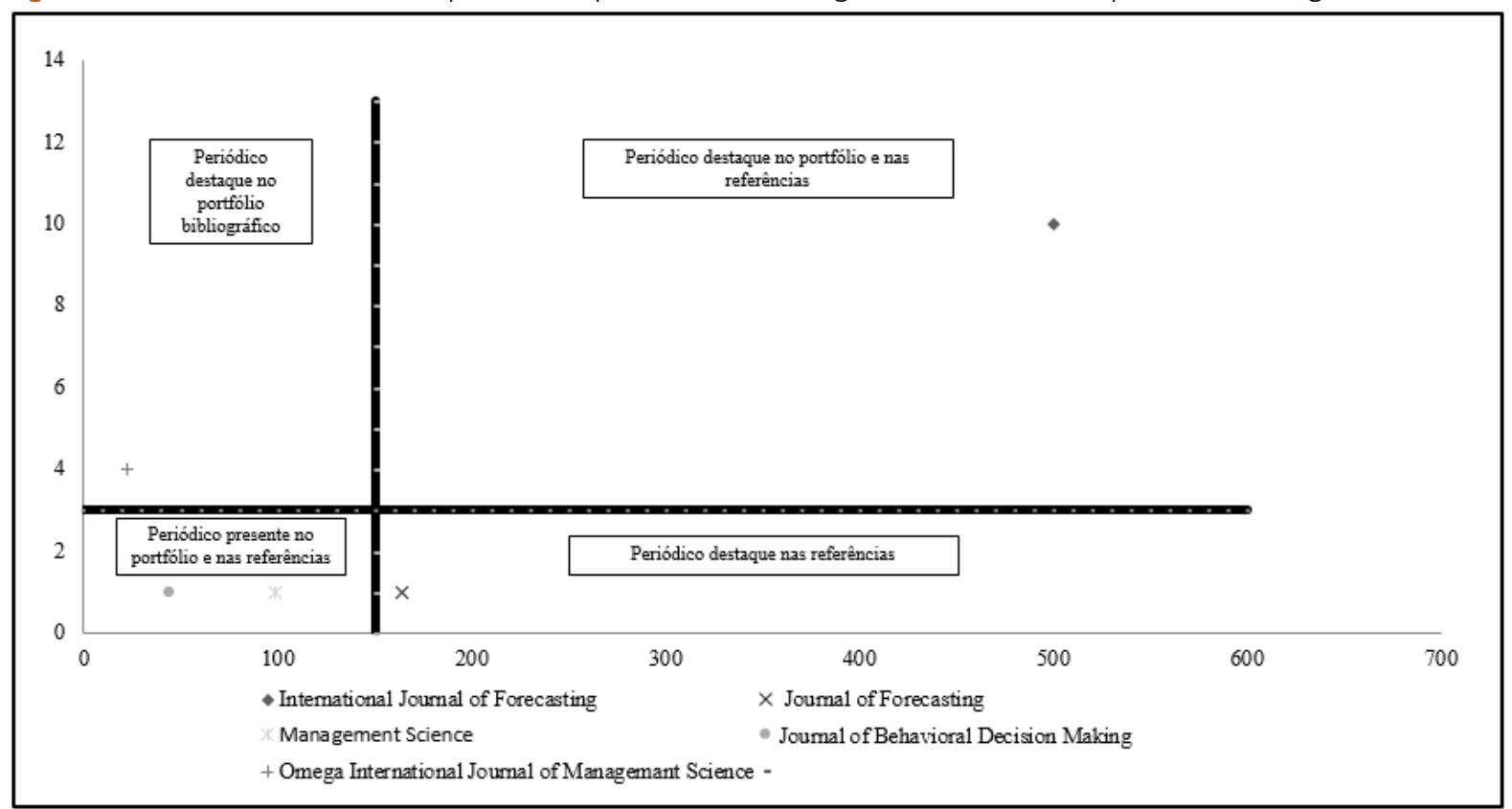

Fonte: Elaborado pelo autor.

\subsection{Análise de conteúdo}

O principal objetivo da análise de conteúdo é encontrar a lacuna científica existente dentro da temática integração de previsões qualitativas e quantitativas com ajuste de especialistas, ou seja, qual será a contribuição científica que a pesquisa trará para a academia.

Diante disso, a análise de conteúdo é conduzida dentro de uma análise categorial, levando em conta os critérios expostos no Quadro 1 (Bardin, 2011). Para gerar as categorias foram utilizados os 21 artigos do portfólio bibliográfico. Assim, as categorias adotadas, de acordo com o conteúdo de cada artigo foram: (i) revisões, resumos ou análise teórica; (ii) abordagem qualitativa ou quantitativa; (iii) método de integração; (iv) estruturação dos julgamentos; e (v) melhorias nas previsões.

Os artigos que sintetizam a análise de conteúdo estão separados em quatro Quadros 3, 4; 5 e 6 em que a primeira apresenta a categorização dos artigos em: revisões, resumos ou análise teórica. Já nas outras três, a categorização apresentada é: abordagem qualitativa e quantitativa; método de integração; estruturação dos julgamentos; e melhorias nas previsões.

Dentre os 21 artigos analisados, o Quadro 3, sintetiza o enquadramento de oito artigos referente a revisão da literatura, resumos ou análise teórica. Sendo que quatro deles categorizam-se como revisão da literatura, sendo eles: Webby \& O’Connor (1996), examina o papel do julgamento na previsão de séries temporais; já Goodwin (2002), apresenta uma revisão da literatura sobre a eficácia da integração de métodos estatísticos com julgamentos em previsões pontuais de curto prazo. Lawrence et al. (2006), realiza uma revisão da literatura dos últimos 25 anos sobre o julgamento humano nas previsões e Gooijer \& Hyndman (2006) realizaram uma revisão da literatura dos últimos 25 anos de pesquisas que envolvem previsões com séries temporais.

Os artigos de Sanders \& Manrodt (2003) e Sanders \& Ritzman (2004), categorizam-se como análises teóricas. O primeiro propõe um modelo conceitual para identificar os motivos que levam as empresas a adotar sistemáticas de previsão de demanda voltadas ao julgamento, em detrimento das previsões via modelagem 
quantitativa. O segundo, tem por objetivo desenvolver quatro metodologias de integração de previsões qualitativas e quantitativas.

Por fim os últimos dois artigos do Quadro 3, categorizam-se como resumos da literatura em que Armstrong (2006) resume o que foi aprendido nos últimos 25 anos sobre a precisão dos métodos de previsão e ainda destaca sete métodos bem estabelecidos que mostraram melhorar a precisão das previsões. Por sua vez, Green \& Armstrong (2011), resumem o progresso substancial na previsão da demanda, descrevendo primeiro métodos baseados em evidências e, em seguida, descrevendo os princípios para selecionar os melhores métodos de previsão de demanda em certas condições de problemas.

Os outros treze artigos analisados são apresentados, nas Quadros 4; 5 e 6, os quais são categorizados em: ii) abordagem qualitativa e quantitativa; iii) método de integração; iv) estruturação dos julgamentos; e v) melhorias nas previsões. Diante disso, somente dois artigos não trabalham com métodos quantitativos de previsão, sendo eles Goodwin (1996) e Fischer \& Harvey (1999). Os outros onze artigos utilizam a abordagem quantitativa para prever a demanda. Sendo que desses quatro artigos fazem uso de modelos ARIMA, são eles: Lobo \& Nair (1990); Wolfe \& Flores (1990); Flores et al. (1992) e Makridakis et al. (1993). Já os artigos Collopy \& Armstrong (1992); Makridakis et al. (1993); Sanders \& Ritzman (1995); Sanders (1997); Goodwin \& Fildes (1999); Goodwin (2000) e Fildes et al. (2009) utilizam técnicas de SE. Song et al. (2013), trabalham com modelos econométricos e autorregressivo de atraso distribuído (ADLM).

Os Quadros 4; 5 e 6 permitem ainda categorizar os artigos quanto à utilização da abordagem qualitativa, ou seja, que fazem uso de previsões via julgamento de especialistas ou combinação dessas. Dos treze artigos, cinco não utilizam a abordagem qualitativa, são eles: Wolfe \& Flores (1990); Flores et al. (1992); Collopy \& Armstrong (1992); Fildes et al. (2009) e Song et al. (2013). Mas outros oito artigos utilizam, sendo que cinco utilizam somente previsões via julgamento, são eles: Lobo e Nair (1990); Sanders \& Ritzman (1995); Goodwin (1996); Goodwin \& Fildes (1999); Goodwin (2000) e três além de previsão via julgamento combinam essas previsões, são eles: Makridakis et al. (1993); Sanders (1997) e Fischer \& Harvey (1999).

A fim de identificar quais artigos utilizam métodos de integração, é possível por meio dos Quadros 4; 5 e 6 observar que os trabalhos de Wolfe e Flores (1990); Flores et al. (1992); Goodwin \& Fildes (1999); e Fischer \& Harvey (1999); Fildes et al. (2009) e Song et al. (2013) utilizam ajustes via especialistas. Já os trabalhos de Lobo e Nair (1990); Collopy \& Armstrong (1992); Sanders \& Ritzman (1995); Sanders (1997) e Goodwin (2000) fazem uso da combinação para integrar a previsão subjetiva com a objetiva.

As últimas duas categorizações tratadas nos Quadros 4; 5 e 6, referem-se à estruturação dos julgamentos e a melhoria das previsões. Destaca-se que somente três artigos utilizam a abordagem de estruturação de julgamentos, são eles: Wolfe \& Flores (1990) usam a técnica Processo Analítico Hierárquico (AHP). Já Flores et al. (1992) fazem um comparativo entre a técnica AHP e a técnica do centroide. 


\section{Quadro 3 - Enquadramento dos artigos em: revisões, resumos ou análise teórica}

Autores

Os autores procuram focalizar, no presente artigo, uma revisão da literatura que examina papel do julgamento na previsão de séries temporais. Para isso, examinaram artigos em que o julgamento humano foi integrado com os dados estatísticos ou integrados com métodos de previsão estruturados. Para fazer isso de forma unificada, desenvolveram um enquadramento metodologico que classifica a integração de previões objetivas em quatro abordagens: (i) construção de modelos; (ii) decomposição baseada em opinião; (iii) ajuste baseado na opinião; e (iv) combinação de previsão. Além disso, os autores sugerem que as previsões mecânica objetiva sejm sintetizadas com as habilidades do julgamento subjetivo, a fim de obter o duplo beneficio das duas abordagens.

ก Este artigo apresenta uma revisão da literatura sobre a eficácia da integração de métodos estatísticos com julgamentos em previções pontuais de curto prazo. Para isso, considera a aplicação da integração voluntária, que envolve informações contextuais via julgamento com a integração mecânica, que considera métodos estatístico. Dentro desse cenário, o autor disserta a respeito dos viesses na incorporação do julgamento que podem ser influenciados por motivos particulares. Mesmo assim o autor sugere que embora reconhecendo o poder dos métodos de integração mecânica que excluem o julgamento do processo de integração, que as pesquisas futuras devem se concentrar no sistemas de apoio a tomada de desição que facilitam a integração voluntária.

Apresenta-se uma revisão da literatura dos últimos 25 anos sobre o julgamento humano nas previsões. Os autores observaram um crescimento na utilização de abordagens julgadoras nas previsões e uma mudança na atitude dos pesquisadores referente aos ganhos advindos do julgamento. A revisão, os autores referênciaram 200 estudos sobre previsão de vendas e identificaram duas formas para incorporar o domínio do conhecimento. Na primeira, as previsões são produzidas pelo julgamento individual ou de um grupo. Já na segunda, as previsões são formadas com a união dos julgamentos com as previsões estatísticas. Por fim, os autores também destacam que o julgamento humano trás melhorias na precisão da previsão.

Nesse estudo, os autores realizaram uma revisão da literatura dos últimos 25 anos de pesquisas que envolvem previsões com séries temporais. O trabalho fornece um guia seletivo com aproximadamente 940 artigos dos quais foram referenciados 380 períodicos e 20 livros. A classificação inicial dos artigos baseou-se nos modelos utilizados como por exemplo ARIMA, Suavização Exponencial), além disso outras classificações foram adotadas, artigos com abordagem voltada para combinações de previões e medidas de acurácia. Os autores destacam ainda que a revisão não pretende ser crítica, mas sim um (breve) passeio histórico e pessoal dos principais trabalhos desenvolvidos no período. Por fim, o artigo de revisão trás várias susgestões de trabalhos futuros sobre a previsão envolvendo séries temporais.

Nesse estudo os autores propõem um modelo conceitual para indentificar os motivos que levam as empresas a adotar sistemáticas de previsão de demanda voltadas ao julgamento em detrimento das previsões via modelagem quantitativas. Para isso enviaram um questionário para 2394 empresas sendo que somente 240 responderam. No tratamento dos dados separaram os previsores das empresas em dois grupos: i) previsões via julgamento; ii) previsões via métodos quantitativos. Posteriormente avaliaram os grupos sobre as seguintes lentes: acesso e uso da informação, incerteza de produto e meio ambiente e acesso e uso de software. Por fim compararam os erros de previsão envolvidos em cada situação. Como resultado encontraram que as empresas que fazem uso de métodos quantitativos apresentaram menores erros de previsão comparado as empresas que usam métodos subjetivos. Dessa forma, concluem que isso ocorre devido ao fato dos previsores das empresas que fazem uso de métodos via julgamento terem menos acesso a dados históricos quantificaveis, informações e menor uso de tecnológias.

Este artigo tem por objetivo desenvolver quatro metodologias de integração de previsões qualitativas e quantitativas. São elas: i) ajuste da previsão quantitativa via julgamento; ii) Previsão via julgamento corrigida quantitativamente; iii) combinação das previsões qualitativas e quantitativas; e iv) utiliza o julgamento para seleção e desenvolvimento da previsão quantitativa. A avaliação das metodologias é baseada em questões de comportamento humano, como grau de parcialidade, sensação de propriedade, questões organizacionais de pontualidade e ainda de acordo com a localização da geração de previsão final dentro da organização (setor de operações, marketing ou terceiros). Os resultados encontrados para cada metodologia, indicam quais às condições mais adequadas para uso, considerando as caracteristicas da organização. Para isso fornecem um enquardamento das metodologias com o local da geração da previsão final. Por fim, os autores cocluíram que cada metodologia tem pontos fortes e fracos e que nem todas são apropriadas para cada contexto organizacional.

Este artigo resume o que foi aprendido nos últimos 25 anos sobre a precisão dos métodos de previsão. 0 autor destaca sete métodos bem estabelecidos que mostraram melhorar a precisão, são eles: a) dois desses métodos se aplicam a todos tipos de dados: i) previsões combinadas com uma estimativa redução de erros de 12\%, e ii) a técnica delphi, que melhorou a precisão em 79\%; b) três métodos aplicamse aos dados de secção transversal: i) modelos causais com uma redução de erros de $10 \%$, ii) bootstrapping julgamento em $6 \%$, e o iii) julgamento estruturado em que não tinha estimativa da redução de erros; c) dois métodos se aplicam a dados de séries temporais: i) tendência amortecida com um erro de $5 \%$ de redução, e ii) modelos causais com maior precisão, mais de 3/4 das comparações para médias e previsões de longo alcance. Como sugestão o autor indica que os profissionais devem implementar estes métodos que já estão consolidados na literatura.

Os autores resumem o progresso substancial na previsão da demanda, descrevendo primeiro métodos baseados em evidências e, em seguida, descrevendo princípios para selecionar os melhores métodos de previsão de demanda em certas condições de problemas. Eles resumem os procedimentos para melhorar as previsões, combinando ou ajustando e comunicando incertezas. Diante disso, o artigo resume as principais conclusões sobre o que fazer e o que não fazer para gerar previsões quando os dados quantitativos são escassos: i) usar pesquisas estruturadas de especialistas; ii) pesquisas de intenções; iii) bootstrapping de julgamento; iv) previsão de mercados; v) analogias estruturadas e interação de simulações. Por outro lado quando os dados quantitativos são abundantes usar: i) extrapolação, ii) analogias quantitativas, iii) previsões baseadas em regras e iv) métodos causais. Se a intenção é incorporar conhecimento prévio de especialistas devese usar métodos estruturados. Por fim os autores alertam para evitar o uso de métodos complexos, não validados, e que ignoram o dominio do conhecimento. Finalmente, descreve procedimentos para facilitar a implementação de novos métodos.

Fonte: Elaborado pelo autor. 
Quadro 4 - Enquadramento dos artigos quanto: ii) abordagem qualitativa e quantitativa; iii) método de integração; iv) estruturação dos julgamentos; e v) melhorias nas previsões

\begin{tabular}{|c|c|c|c|c|c|c|}
\hline Autores & Descrição & $\begin{array}{l}\text { Abordagem } \\
\text { Quantitativa }\end{array}$ & Abordagem Qualitativa & $\begin{array}{l}\text { Método de } \\
\text { Integração }\end{array}$ & 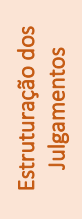 & 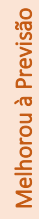 \\
\hline 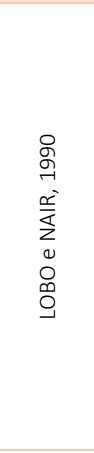 & $\begin{array}{l}\text { Essa pesquisa examinou dois problemas: i) a determinação do } \\
\text { melhor modelo estatístico e ii) a comparação da precisão das } \\
\text { previsões entre modelos estatísticos versus previsões dos analistas } \\
\text { via julgamentos. Dessa forma, investiga-se: quando a precisão das } \\
\text { previsões pode ser melhorada combinando as previsões via } \\
\text { julgamento com previsões de modelos estatísticos amplamente } \\
\text { utilizados na literatura financeira e contabilística. Foram usadas as } \\
\text { seguintes formas de combinação de previsões: i) média aritmética e } \\
\text { média ponderada em que os pesos foram definidos via regressão. } \\
\text { Os dados foram obtidos de } 96 \text { empresas e as séries temporais } \\
\text { utilizadas englobam os ganhos trimestrais de cada uma no período } \\
\text { de } 1976 \text { a 1983. Como resultado os autores descobriram que se as } \\
\text { duas previsões não estiverem perfeitamente correlacionadas, então } \\
\text { a combinação, em média, resultará em uma previsão mais precisa } \\
\text { do que qualquer uma das previsões individuais. }\end{array}$ & $\begin{array}{l}\text { i) Previsão via } \\
\text { ARIMA; } \\
\text { ii) Previsão } \\
\text { via média } \\
\text { simples }\end{array}$ & $\begin{array}{l}\text { i) Previsão via Julgamento fornecida por } \\
\text { empresa de corretagem (considerando a } \\
\text { média de previsões de vários analistas; } \\
\text { ii) Questionário de Investimento por linha de } \\
\text { valor (VL) }\end{array}$ & $\begin{array}{l}\text { Previsão } \\
\text { Combinada } \\
\text { i) via média } \\
\text { aritmética; } \\
\text { ii) média } \\
\text { ponderada }\end{array}$ & $\frac{0}{2 \pi}$ & $\underline{E}$ \\
\hline 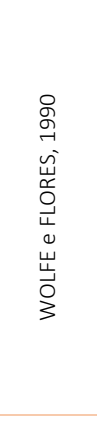 & $\begin{array}{l}\text { Este artigo trabalha com o ajuste via julgamento de previsões } \\
\text { quantitativas. Para isso efetuou previsões utilizado a técnica ARIMA } \\
\text { e posteriormente ajustou essas previsões objetivas com auxilio de } \\
\text { especialistas por meio da abordagem estruturada baseada no } \\
\text { Processo Analitico Hierarquico (AHP). Para executar os trabalhos } \\
\text { foram utlizados os ganhos trimestras de } 32 \text { empresas constantes no } \\
\text { banco de dados da Value Line. Com relação ao ajuste subjetivo } 14 \\
\text { mestrandos em administração de empresas e } 14 \text { análistas de crédito } \\
\text { corporativo foram utilizados. Os autores cocluiram que, as previsões } \\
\text { não foram melhoradas pelo ajuste subjetivo, nos períodos em que } \\
\text { os especialistas tinham níveis mais elevados de informação. Por } \\
\text { outro lado, os resultados mostram que a precisão das previsões } \\
\text { objetivas quando não corrigidas podem ser melhoradas por meio do } \\
\text { ajuste por julgamento. }\end{array}$ & ARIMA & Não & $\begin{array}{l}\text { Ajuste via } \\
\text { especialistas }\end{array}$ & 愛 & $\dot{E}$ \\
\hline 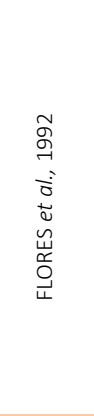 & $\begin{array}{l}\text { A proposta dos autores é realizar um comparativo entre ajustes de } \\
\text { previsões quantitativas via julgamento estruturado. Para isso, } \\
\text { comparam a métodologia AHP utilizada por (WOLFE e FLORES, 1990) } \\
\text { com o método do centroíde, que apresenta custo mais baixo de } \\
\text { implantação e facilidades de uso. Para realizar o comparativo entre } \\
\text { os métodos estruturados, foram utlizados os ganhos trimestrais de } \\
28 \text { empresas constantes no banco de dados da Value Line. Com } \\
\text { relação ao ajuste subjetivo, } 14 \text { estudades de mestrado executivo em } \\
\text { administração comercial e } 14 \text { análistas de crédito corporativo foram } \\
\text { utilizados. Como resultado os autores concluiram que enquanto o } \\
\text { AHP permite um ajuste mais preciso para refletir o julgamento dos } \\
\text { tomadores de decisões o método centróide produz resultados } \\
\text { muito semelhantes e é muito mais fácil de usar no ajuste da } \\
\text { previsão. }\end{array}$ & ARIMA & Não & $\begin{array}{l}\text { Ajuste via } \\
\text { especialistas }\end{array}$ & 高亭 & $\dot{E}$ \\
\hline 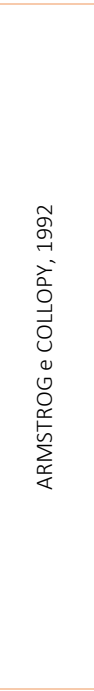 & $\begin{array}{l}\text { Este artigo trata da aplicabilidade da previsão baseada em regras } \\
\text { que usa o julgamento de especialista sobre as características dos } \\
\text { dados. Também trata das forças causais que afetam séries } \\
\text { temporais como insumos no procedimento estatístico. A base de } \\
\text { regras prosposta pelos autores, integra várias estratégias para } \\
\text { extrapolação, entre elas estão: (i) usar recursos da prórpia série para } \\
\text { estabelecer pesos e posteriormente combinar previsões; ii) usar } \\
\text { heurísticas para estabelecer parâmetros para modelos de } \\
\text { suavização exponencial; iii) usar modelos separados para previsões } \\
\text { de longo alcance e curto alcance; iv) amortecimento da tendência } \\
\text { abaixo de certas condições; e v) incorporar o dominio do } \\
\text { conhecimento por meio da extrapolação. O desenvolvimento da } \\
\text { base de regras envolveu a análise dos protocolos de cinco } \\
\text { especialistas em métodos de previsão. Como resultado obteve-se } 99 \\
\text { regras e previsões combinadas a partir de quatro métodos de } \\
\text { extrapolação (a caminhada aleatória, a regressão, o exponencial } \\
\text { linear de Brown Alisamento e suavização exponencial de Holt) de } \\
\text { acordo com regras usando } 18 \text { características das séries temporais. } \\
\text { Os autores concluíram que as previsões para um ano a frente, a } \\
\text { previsão baseada em regras foi } 13 \% \text { mais precisa que a combinação } \\
\text { de previsões com pesos iguais e quando a previsão envolveu seis } \\
\text { anos a frente a melhoria foi de } 42 \% \text {. Mas nos casos que as regras } \\
\text { não foram seguidas não ocorreu melhoria nas previsões }\end{array}$ & $\begin{array}{l}\text { Modelos de } \\
\text { Suavização } \\
\text { Exponencial }\end{array}$ & Não & $\begin{array}{l}\text { Previsão } \\
\text { Combinada } \\
\text { i) via média } \\
\text { ponderada; }\end{array}$ & $\frac{20}{2 \pi 0}$ & $\dot{E}$ \\
\hline
\end{tabular}

Fonte: Elaborado pelo autor. 
Quadro 5 - Continuação do enquadramento dos artigos: ii) abordagem qualitativa e quantitativa; iii) método de integração; iv) estruturação dos julgamentos; e v) melhorias nas previsões

Estruturação

dos Julgamentos

Melhorou à

Integração Julgamentos

A M2-competição tem por objetivo determinar exatidão de vários métodos de previsão, iniciou em 1987 e terminou em 1990. É um estudo empírico organizado para avaliar dados em situações reais em que os previsores podem usar informações adicionais para melhorar a exatidão preditiva de métodos quantitativo. Essas informações pode envolver $m$ conhecimento interno como por exemplo, (avaria da न máquina, um ataque futuro de um importante ¿. $\quad$ concorrente ou aumento acentuado de preços, etc). \pm Por estas razões, foi decidido realizar uma competição $\frac{\omega}{\bar{y}} \quad$ com dados do presente e exigindo previsões para o futuro. Para concretizar isso, foram distribuidas 29 futuro. Para concretizar isso, foram distribuidas 29
séries reais oriundas de quatro empresas, os dados foram manipulados por um constante multiplicativa e cinco previsores fizeram previsões que posteriormete foram comparadas com os métodos quantitativos. Os autores concluiram que os métodos simples de previsão de demanda podem ser usados com segurança na previsão de séries reais, pois são métodos com baixo custo e de fácil aplicação e geram previsões satisfatorias.

Esta pesquisa investiga os benefícios gerados na precisão das previsões via combinação de métodos estatísticos com o julgamento humano. Para isso, dois grupos de previsores são utilizados um com คू conhecimento contextual, que envolve os previsores z da empresa e outro grupo com conhecimento técnico em métodos de previsãos, que utiliza estudades de graduação. São utilizados no trabalho 22 séries temporais, que abragem um périodo de 3 anos, coletados de um armazém público. Como resultado os autores encontraram que, uma relação entre a inclusão do conhecimento contextual na combinação, depende do nível de variabilidade presentes nas séries temporais. Sendo assim quanto mais variabilidade estiver presente nos dados, mais conhecimento contextual é necessário.

Este artigo sugere um procedimento que envolve correção estatística. Para isso, o autor aplica a análise de regressão para prever erros futuros, e esses erros passam por uma correção estatística usando a 6 correção linear ótima de Theil e posteriormente os ने erros previstos são adicionandos aos valores originais.

¿ O procedimento de correção foi aplicado nas,

"previsões de vendas via julgamento" de uma empresa - que projeta e fábrica equipamentos industriais. O autor concluiu que a correção foi bem sucedida quando as séries apresentaram altos níveis de ruído. Em particular, para a série de ruído branco, a correção teve o efeito de suavizar a variação nas previsões de julgamento causadas pelos previsores.

Este estudo avalia o impacto do feedback sobre a precisão da previsão de séries temporais em quatro cenários de julgamento preditivo, são eles: i) previsões individuais de julgamento; ii) previsões de

ने grupos interativos; iii) combinações do julgamento जิ combinações de julgamento individual com previsões 㟧 quantitativas. Para atingir tal objetivo a autora avalia impacto de fornecer informações sobre padrões de dados da série temporal e nível de ruído para 98 alunos da área de negócios que geraram as previsões individuais. Essas previsões foram combinadas via média aritmérica 3 a 3 para formar a previsão de grupos. Ainda a autora gerou previsões quantitativas
Familia de ARIMA;Família Suavização Esponencial;Métodos ingenuos

Previsões
individual via
julgamentoii)
Combinação das
previsões
individuais via
média aritmética;

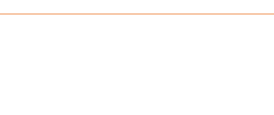

Suavização

Exponencial de Holt

i) Previsões geradas pelos planejadores do Armazém - Com conhecimento contextual;

ii) Previsão gerada por Estudantes com conhecimento das técnicas objetivas.
Suavização Exponencial Simples

Suavização Exponencial de Winters
Previsão individual via Julgamento;

ii) Combinação das previsões individuais em grupos de 3, via média aritmética;
Combinada

aritmética;

i) Previsão

gerada via

Previsão
Previsão

i) via média

Correção estatística

Combinada

i) via média

Sim aritmética; 


\begin{tabular}{|c|c|c|c|c|c|c|}
\hline & $\begin{array}{l}\text { por meio das técnicas de Suavização Exponencial e } \\
\text { combinou-as (via média aritmética) com a previsão } \\
\text { individual via julgamento. Para executar o trabalho a } \\
\text { autora gerou } 8 \text { séries temporais artificiais com } 60 \\
\text { observações. Os resultados encontrados mostram que } \\
\text { feedback leva a melhorias na precisão das previsões } \\
\text { para todos processos de previsão testados, } \\
\text { particularmente para séries com alto nível de ruídos. }\end{array}$ & & & & & \\
\hline 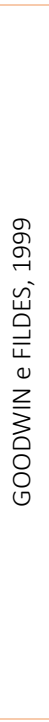 & $\begin{array}{l}\text { Os autores conduziram experimentos de laboratório } \\
\text { para simular problemas de previsão de vendas em } \\
\text { condições (normais, promoção e pós-promoção). Para } \\
\text { isso as séries temporais geradas foram investigadas } \\
\text { em diferentes condições de pertubações: i) } \\
\text { complexidade da série temporal; ii) poder preditivo } \\
\text { com pertubação nas vendas; iii) monitoramento } \\
\text { posterior da pertubação das vendas; e iv) tipo de } \\
\text { feedback. Nesse último caso os previsores foram } \\
\text { convidados a produzir previsões e durante o } \\
\text { experimento, eles receberam: i) um feedback de } \\
\text { resultados simples, ii) uma previsão estatística de } \\
\text { séries temporais, e iii) uma previsão estatística, } \\
\text { juntamente com uma explicação regular da sua } \\
\text { fundamentação. Os autores concluíram que os } \\
\text { julgamentos feitos pelos analistas que realizaram a } \\
\text { integração voluntária foi ineficientemente. Eles } \\
\text { fizeram ajustes prejudiciais para as previsões } \\
\text { estatísticas confiável e ignoraram essas previsões em } \\
\text { períodos quando elas formaram uma linha de base } \\
\text { ideal para ajuste. }\end{array}$ & $\begin{array}{l}\text { Suavização Exponencial } \\
\text { Simples } \\
\text { Suavização Exponencial } \\
\text { de Holt - Winters }\end{array}$ & $\begin{array}{l}\text { i) Previsão } \\
\text { individual via } \\
\text { Julgamento; }\end{array}$ & $\begin{array}{l}\text { Ajuste via } \\
\text { especialistas }\end{array}$ & Não & Não \\
\hline
\end{tabular}

Fonte: Elaborado pelo autor. 
Quadro 6 - Continuação do enquadramento dos artigos: ii) abordagem qualitativa e quantitativa; iii) método de integração; iv) estruturação dos julgamentos; e v) melhorias nas previsões

\begin{tabular}{|c|c|c|c|c|c|c|}
\hline Autores & Descrição & $\begin{array}{l}\text { Abordagem } \\
\text { Quantitativa }\end{array}$ & Abordagem Qualitativa & $\begin{array}{l}\text { Método de } \\
\text { Integração }\end{array}$ & $\begin{array}{l}\text { Estruturação dos } \\
\text { Julgamentos }\end{array}$ & $\begin{array}{c}\text { Melhorou à } \\
\text { Previsão }\end{array}$ \\
\hline 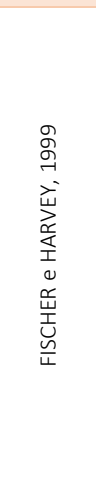 & $\begin{array}{l}\text { A abordagem utilizanda nesse artigo consiste em realizar três experimentos } \\
\text { que visam responder aos seguintes questionamento: i) O feedback de } \\
\text { resultados facilita a aprendizagem na combinação de previsão ou não tem } \\
\text { efeito?; ii) Se o feedback do resultado tiver um efeito, informações } \\
\text { adicionais projetadas podem ajudar os julgadores a apreender relações de } \\
\text { critério e fornecer mais beneficios ou se tornará redundante?; iii) Como } \\
\text { melhorar a precisão da combinação de julgamento de previsões comparadas } \\
\text { com as combinações produzido por uma média simples sob vários diferentes } \\
\text { condições de feedback? Os autores concluíram que no primeiro } \\
\text { experimento os julgadores quando recebem informações, eles aprendem } \\
\text { a poderar separadamente as previsões. Já com o segundo e terceiro } \\
\text { experimento eles forneceram aos julgadores informações sobre erros } \\
\text { cometidos nas previsoões individuais. Os resultados mostram que fornecer } \\
\text { informações sobre seus MAPE atualizados para cada período permite aos } \\
\text { previsores combinar suas previsões de forma a superar as previsões por } \\
\text { média simples. }\end{array}$ & Não & $\begin{array}{l}\text { Previsões individual via } \\
\text { julgamentoii) Combinação } \\
\text { das previsões individuais } \\
\text { via média aritmética; }\end{array}$ & $\begin{array}{l}\text { Ajuste via } \\
\text { especialistas }\end{array}$ & Não & Sim \\
\hline 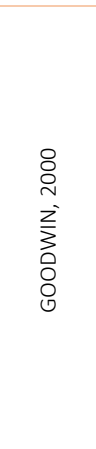 & $\begin{array}{l}\text { O autor desenvolve um experimento de laboratório e dois estudos de campo } \\
\text { para comparar a precisão de três métodos de integração entre previsões via } \\
\text { julgamento com métodos estatísticos. Nos três estudos, os especialistas } \\
\text { tiveram acesso exclusivo a informações contextuais. Os três métodos } \\
\text { comparados foram: (i) correção estatística de vieses de julgamento usando } \\
\text { a correção linear ótima de Theil; (ii) combinação de previsões de julgamento } \\
\text { e previsões estatísticas de séries temporais usando uma média simples e (iii) } \\
\text { correção de viés de julgamento seguido de combinação. Para atingir tal fim, } \\
\text { o autor delineia a metodologia em um experimento de laboratório e } \\
\text { posteriormente aplica a metodológia em dados de vendas de uma empresa } \\
\text { têxtil e uma empresa de engenharia ambas da europa. Como resultados o } \\
\text { autor conclui que houve pouca evidência em qualquer um dos estudos de } \\
\text { que vale a pena combinar previsões de julgamento com uma previsão } \\
\text { estatística de séries temporais - simplesmente corrigir vieses de julgamento } \\
\text { geralmente era suficiente para obter melhorias na precisão }\end{array}$ & $\begin{array}{l}\text { Suavização } \\
\text { Exponencial } \\
\text { Simples } \\
\text { Suavização } \\
\text { Exponencial de } \\
\text { Holt - Winters }\end{array}$ & $\begin{array}{l}\text { i) Previsão individual via } \\
\text { Julgamento; }\end{array}$ & $\begin{array}{l}\text { Previsão } \\
\text { Combinada } \\
\text { i) via média } \\
\text { aritmética; }\end{array}$ & Não & Não \\
\hline 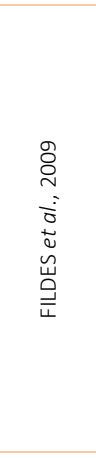 & $\begin{array}{l}\text { Nesse estudo os autores desenvolve uma temática envolvendo previsão de } \\
\text { demanda quantitativa que posteriormente é ajustada por especialistas. } \\
\text { Dentro dessa perspectiva os autores indagam: fazer ajustes subjetivos pode } \\
\text { efetivamente melhoram a precisão? e alguns tipos de ajuste são mais } \\
\text { efetivos do que outros? Para investigar isso, os autores coletaram dados em } \\
\text { quatro empresas dos setores (varejo, produtos domésticos, farmacêutica e } \\
\text { de alimentos) referente a cadeia de suprimentos, totalizando uma análise } \\
\text { de mais de } 60.000 \text { previsões. Concluiram que em três das empresas, em } \\
\text { média, os ajustes de julgamento aumentaram a precisão. No entanto, uma } \\
\text { análise detalhada revelou que, os ajustes maior tendem a levar a maiores } \\
\text { melhorias na precisão e os ajustes menores geralmente danificaram a } \\
\text { precisão. Além disso, os ajustes positivos, realizados para cima, foram muito } \\
\text { menos propensos a melhorar a precisão do que os ajustes negativos. Devido } \\
\text { ao fato de os ajustes serem feitos com mais frequência na direção errada, } \\
\text { sugere um viés para o otimismo. }\end{array}$ & $\begin{array}{l}\text { Geradas por } \\
\text { software } \\
\text { estátisticos que } \\
\text { utiliza técnicas } \\
\text { da Família } \\
\text { Suavização } \\
\text { Exponencial }\end{array}$ & Não & $\begin{array}{l}\text { Ajuste via } \\
\text { especialistas }\end{array}$ & Não & Sim \\
\hline 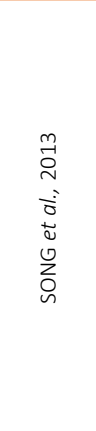 & $\begin{array}{l}\text { Este artigo apresenta um sistema de previsão de demanda de turismo } \\
\text { baseado na web (TDFS) que é projetado para prever a demanda turística de } \\
\text { Hong Kong. O sistema considera as seguintes séries temporais: i) chegadas } \\
\text { de turistas, ii) despesas turísticas totais e setoriais, e iii) a demanda por } \\
\text { quartos de hotel. O processo TDFS compreende três estágios: análise } \\
\text { preliminar de dados, geração de previsões quantitativas e ajustes via } \\
\text { julgamentos. Para analisar o desempenho do sistema de demanda proposto } \\
\text { os autores realizaram um estudo de caso recente envolvendo as previsões } \\
\text { quantitativas, ajustado por um painel de especialistas via técnica DELPHI em } \\
\text { que fornecem previsões precisas sobre a procura turística da cidade Hong } \\
\text { Kong. Os resultados mostram que esta combinação de previsões } \\
\text { quantitativas e julgamento melhoram a precisão global do forecasting. }\end{array}$ & $\begin{array}{l}\text { Modelo } \\
\text { Econométrico } \\
\text { Modelo } \\
\text { autoregressivo } \\
\text { de atraso } \\
\text { distribuido } \\
\text { (ADLM) }\end{array}$ & Não & $\begin{array}{l}\text { Análise de } \\
\text { Cenários } \\
\text { Ajuste via } \\
\text { especialistas } \\
\text { Feedback e } \\
\text { registro das } \\
\text { alterações } \\
\text { pelos } \\
\text { especialistas } \\
\text { A previsão feita } \\
\text { pelos } \\
\text { especialistas é } \\
\text { obtida pela } \\
\text { média. }\end{array}$ & DELPHI & Sim \\
\hline
\end{tabular}

Fonte: Elaborado pelo autor.Por fim, Song et al. (2013) em seu artigo aborda a utilização da técnica DELPHI. Referente à melhoria das previsões somente dois artigos não obtiveram êxito Goodwin \& Fildes (1999) e Goodwin (2000).

Assim, diante do exposto, este estudo procura responder ao seguinte questionamento: Como encontrar a lacuna científica dentro da temática integração de métodos quantitativos e qualitativos para previsão de demanda com ajuste de especialistas? Por meio da análise de conteúdo de 21 artigos do portfólio bibliográfico foi possível evidenciar que apesar dos esforços até o presente momento, os artigos estão concentrados em melhorar a precisão das previsões, como combinar as previsões e de que forma fazer os ajustes dos julgamentos dos especialistas, pois dos 21 artigos 18 trabalham sob esse enfoque, são eles: Lobo \& Nair (1990); Collopy \& 
Armstrong (1992); Makridakis et al. (1993); Sanders \& Ritzman (1995); Webby \& O'Connor (1996); Goodwin (1996); Sanders (1997); Fischer \& Harvey (1999); Goodwin \& Fildes (1999); Goodwin (2000); Goodwin (2002); Sanders \& Manrodt (2003) e Sanders \& Ritzman (2004); Lawrence et al. (2006); Gooijer \& Hyndman (2006); Armstrong (2006); Fildes et al. (2009); e Green \& Armstrong (2011).

No entanto, pouca atenção da literatura é dada para métodos de estruturação dos julgamentos via métodos multicritério de apoio à tomada de decisão, sendo que somente três artigos trabalharam com essa temática, são eles: Wolfe \& Flores (1990); Flores et al. (1992); Song et al. (2013). Portanto, a oportunidade encontrada e que será abordada nessa pesquisa envolve a seguinte temática: integração de métodos quantitativos e qualitativos para previsão de demanda com ajuste de especialistas via métodos multicritério de apoio à tomada de decisão.

\section{Conclusão}

O presente artigo buscou, com a utilização da metodologia empregada, construir um portfólio bibliográfico, selecionar por meio da análise bibliométrica os principais autores, periódicos e artigos e também encontrar uma lacuna científica dentro da temática: integração de métodos quantitativos e qualitativos para previsão de demanda com ajuste de especialistas.

A fim de atender os objetivos propostos, obteve-se um portfólio bibliográfico com 21 artigos, sendo que o periódico de destaque no portfólio bibliográfico e nas referências é o International Journal of Forecasting. Além disso, foi possível identificar que os autores de destaque dentro desse portfólio bibliográfico e nas referências são: Armstrong S. J.; Goodwin, P. e Lawrence, M. No entanto, o artigo com o maior reconhecimento científico é dos autores (Gooijer, J. G. \& Hyndman, R. J.) intitulado "25 years of time series forecasting" com 412 citações. Com relação à análise de conteúdo, foi possível encontrar a lacuna científica sendo que a temática a ser abordada é a integração de métodos quantitativos e qualitativos para previsão de demanda com ajuste de especialistas via método multicritério de apoio à tomada de decisão.

Assim, fica evidente que o objetivo proposto no presente artigo foi alcançado e que, por meio desse, foi possível construir conhecimento sólido sobre a bibliometria e análise do conteúdo do tema proposto. Finalmente, o presente artigo apresenta como contribuição científica um processo estruturado sobre a temática pesquisada como também uma sugestão de categorização. Como sugestão para trabalhos futuros, é possível realizar a pesquisa utilizando outras palavras-chave, ampliar a utilização das bases de dados pesquisadas e desenvolver uma pesquisa com a lacuna científica encontrada "integração de métodos quantitativos e qualitativos para previsão de demanda com ajuste de especialistas via método multicritério de apoio à tomada de decisão.

\section{Referências}

Bardin, L. (1977). Análise de conteúdo. Lisboa: Edições Setenta.

Bardin, L (2011). Análise de Conteúdo. São Paulo: 70 eds.

Bortoluzzi, S.C., Ensslin, S.R., Ensslin, L., Valmorbida. S.M.I. (2011). Avaliação de desempenho em redes de pequenas e médias empresas: Estado da arte para as delimitações postas pelo pesquisador. Estratégia \& Negócios, 4, 202-222.

Carlomagno, M. C., Rocha, L. C. (2016). Como criar e classificar categorias para fazer análise de conteúdo: uma questão metodológica. Revista Eletrônica de Ciência Política, 7(1), 173-188. 
Ensslin, L., Ensslin, S.R., Lacerda, R.T.O., Tasca, J.E. (2010). Proknow-C, Knowledge Development Process Constructivist. Processo técnico com patente de registro pendente junto ao INPI. Brasil.

Ensslin, L., Ensslin, S. R., Rocha, S., Marafon, A. D., Assad, T. (2013). Modelo multicritério de apoio à decisão construtivista no processo de avaliação de fornecedores. Revista Produção, 23(2), 402-421.

Green K. C; Armstrong, J. S. Demand forecasting: evidence-based methods. Wharton University of Pensylvania. Disponível em: https://marketing.wharton.upenn.edu/index.cfm/research/researchlisting/?whdmsaction=publications. list\&pubFilter=all\&pubYearFilter=2012. Acessado em 22/06/2016.

Graefe, A., Armstrong, S. J., Randall, J. J. Jr., Cuzán, A. G. (2014). Combining forecast: An application to elections. International Journal Forecasting, 30(4), 3-64.

Goodwin, P. (2002). Integrating management judgment and statistical methods to improve short-term forecast. Omega, 30(2), 127-135.

Google Acadêmico. Disponível em: http://scholar.google.com.br/. Acesso em: jun. 2016.

Gooijer, J. G., Hyndman, R. J. (2006). 25 years of time series forecasting. International Journal of Forecasting, 22, 443-473.

Gularte, L. C. P., Bortoluzzi, S. C., Lima, J. D., Pinto, M. A. N., Goffi, A. S. (2018).

Análise bibliométrica e sistêmica da literatura sobre viabilidade econômica-financeira, gestão e sustentabilidade da reciclagem de resíduos da construção civil. Exacta, 16(4), 45-58.

Lacerda, R. T. O., Ensslin, L., \& Ensslin, S. R. (2012). Uma análise bibliométrica da literatura sobre estratégia e avaliação de desempenho. Gestão \& Produção, 19 (1), 59-78.

Lawrence, M., Goodwin, P., O'connor, M., Onkal, D. (2006). Judgmental forecasting: A review of progress over the last 25 years. International Journal of forecasting, 22, 493-518.

Lizot, M., Júnior, P. P. A., Magacho, C. S., Bortoluzzi, S. C. (2015). Avaliação de Desempenho na Gestão da Produção: Análise Bibliométrica e Sistêmica da Literatura Internacional. Congresso de Contabilidade. Florianópolis - UFSC.

Mancuso, A. C. B., Werner, L. (2013). Review of combining forecasts approaches. Independent Journal of Management \& Production (IJM\&P), 4910.

Marafon, A. D., Ensslin, L., Lacerda, R. T. O., Ensslin, S. R. (2012). Revisão Sistêmica da Literatura Internacional sobre Avaliação de Desempenho na Gestão de P\&D. Revista Gestão Industrial, 8(3), 1-43.

Makridakis, S., Wheelwright, S., Hyndman, R. J. (1998). Forecasting methods and applications. 3 ed. New York: John Wiley \& Sons.

Meireles, M. R. G., Cendón, B. V. (2010). Aplicação prática dos processos de análise de conteúdo e de análise de citações em artigos relacionados às redes neurais artificiais. Inf. Inf., 15(2), 77 - 93.

Pellegrini, F. R., Fogliatto, F. S. (2001). Passos para implantação de sistemas de previsão de demanda - Técnicas e estudo de caso. Revista Produção, 11(1), 43-64.

Santos, G. Q. V., Junior, J. A. M., Bernardo, Y. N. S. (2015). Previsão de demanda: revisão bibliográfica e análise acadêmica atual. XXXV ENCONTRO NACIONAL DE ENGENHARIA DE PRODUÇÃO. Fortaleza, Brasil.

Sanders, N. R., Ritzman, L. P. (2004). Integrating judgmental and quantitative forecasts: methodologies for pooling marketing and operations information. International Journal of Operations \& Production Management, 24, 514-529.

Saccani, N. (2011). Forecasting for capacity management in call centres: combining methods, organization, people and technology. Journal of Management Mathematics, 24,189-207. 
Tasca, J. E., Ensslin, L., Ensslin, S. R., Alves, M. B. M. (2010). An approach for selecting a theoretical framework for the evaluation of training programs. Journal of European Industrial Training, 34, 631-65.

Urquiza, M. A., Marques, D. B. (2016). Análise de conteúdo em termos de Bardin aplicada à comunicação corporativa sob o signo de uma abordagem teórico-empírica. Entretextos, 16(1), 115-144.

Vilela, L.O. (2011). Aplicação do Proknow-C para seleção de um portfólio bibliográfico e análise bibliométrica sobre avaliação de desempenho da gestão do conhecimento. Revista Gestão Industrial, 8(1), 76-92.

Wallis, K. F. (2011). Combining forecasts - forty years later. Applied Financial Economics, 21, 33-41.

Werner, L. (2004). Um modelo composto para realizar previsão de demanda através da integração da combinação e de previsões e ajustes baseados na opinião. Tese de Doutorado. UFRGS. Porto Alegre, Brasil.

Werner, L., Ribeiro, J. L. D. (2006). Modelo composto para prever demanda através da integração de previsões. Prod. [online], 16(3), 493-509.

Webby, R., O'connor, M. (1996). Judgmental and Statistical Time Series Forecasting: A review of the Literature. International Journal of Forecasting, 2(1), 91-118.

\section{Para referenciar este texto}

Ferro, W. A., Lima, J. D. de, Schenatto, F. J. A., Trentin, M. G., \& Bortoluzzi, S. C. (2020). Estudo bibliométrico e sistêmico da literatura sobre a integração de métodos quantitativos e qualitativos na previsão de demanda com ajuste de especialistas. Exacta, 18(2), 311-333.

https://doi.org/10.5585/ExactaEP.v18n2.8739. 